\title{
Factors affecting light energy transfer in some samarium complexes
}

\author{
Esam Bakier and M. S. A. Abdel-Mottaleb ${ }^{\dagger}$ \\ Photoenergy Center, Ain Shams University, 11566 Abbassia, Cairo, Egypt
}

\begin{abstract}
The photophysical properties of samarium ion in presence of 7-Acetoxy Coumarin 3-Carboxylic acid (ACC) or 1-(4-methoxyphenyl) 3-(4-t-butyl phenyl) 1,3-propandione (MBPK), which act as antenna of near-UV radiation, are studied in different homogeneous, and heterogeneous media as well as in rigid polymethylmethacrylate matrix (PMMA). High quantum yield value of the sensitized emission of ( $\mathrm{Sm}^{3+}$-(ACC)) and $\left(\mathrm{Sm}^{3+}-(\mathrm{MBPK})\right)$ in N,N-dimethylformamide and PMMA matrix are obtained pointing to an efficient ligandto-metal energy transfer. Moreover, luminescence mappings for pattern recognition analysis that could be profitably exploited as a useful identification method in clinical chemistry and biochemistry have been obtained from which the nature of the solvent and/or the ligand is clearly identified by inspection of the corresponding excitation/emission matrix maps.
\end{abstract}

\section{INTRODUCTION}

The importance of energy transfer processes in solution of lanthanide complexes increases due to their potential applications in luminescence assays for biochemistry, liquid lasers, and electroluminescence and telecommunication devices as well as for trace determination of lanthanide ions [1-3].

The phenomena of energy transfer from ligand to lanthanide ions result, consequently, in a great enhancement of lanthanide ion luminescence (ligand sensitized luminescence) [4-7]. Lanthanide ions are chelated with ligands that have intense absorption bands in the UV region. In these systems, intense ion luminescence originates from the intramolecular energy transfer through the excited state of the ligand to the emitting level of the lanthanide ion. Lehn [8] named this phenomenon the "antenna effect" and proposed that such complexes could be seen as light conversion molecular devices because they are able to transform light absorbed by ligand into emitted light by the ion via an intramolecular energy transfer.

The chelate serves several purposes: it provides a scaffold for covalently attaching the antenna in close proximity to the lanthanide facilitating the transfer of energy from the antenna to lanthanide; it displaces water from the primary coordination sphere of lanthanide, which would otherwise quench the lanthanide luminescence $[9,10]$. The low energy excited states responsible for near-IR region (NIR) emission are easily quenched by nearby $\mathrm{O}-\mathrm{H}, \mathrm{N}-\mathrm{H}$ and $\mathrm{C}-\mathrm{H}$ oscillators of the solvent, play an important role in nonradiative energy dissipation from the lanthanide excited state [11].

The two most useful lanthanides, europium and terbium, have unusual spectroscopic characteristics, including millisecond lifetime, sharply spiked (few

†E-mail: solar@link.net

$\mathrm{nm}$ ) emission spectra, and large (> $150 \mathrm{~nm})$ Stokes' shifts $[12,13]$. Europium and terbium ions are used as structural and analytical luminescent probes and stains for bimolecular systems [2]. These probes are of considerable interest in clinical diagnostics, fluoroimmunoassays, life-sciences, drug-screening assays and show considerable promise in luminescence imaging and as sensors for certain bioactive ions [14-16].

In this article, the photophysical properties of the sensitized luminescence emission of samarium ion induced by the antenna chromophores, namely 7-Acetoxy Coumarin 3-Carboxylic acid (ACC) and 1-(4-methoxyphenyl) 3-(4-t-butyl phenyl) 1,3 propandione (MBPK) in different solvents, mixed solvent of methanol/N,N-dimethylformamide, microheterogenous media and rigid media of polymethylmethacrylate matrix (PMMA) are studied and discussed. The luminescence quenching efficiency is evaluated by Stern-Volmer constant $\left(\mathrm{K}_{\mathrm{SV}}\right)$ in methanol/N,Ndimethylformamide mixed solvent. This will provide information about the mechanism of energy transfer.<smiles>CC(=O)Oc1ccc2cc(C(=O)O)c(=O)oc2c1</smiles>

7-Acetoxy Coumarin 3-Carboxylic Acid (ACC)<smiles>COc1ccc(C(=O)CC(=O)c2ccc(C(C)(C)C)cc2)cc1</smiles>

1-(4-methoxyphenyl) 3-(4-t-butylphenyl) 1,3-propandione (MBPK)

Moreover, luminescence mappings for pattern recognition analysis will be obtained and discussed.

\section{EXPERIMENTAL}

Samarium (III) chloride anhydrous (Aldrich, 99.99\%) was used as received and 7-Acetoxy Coumarin 3-Carboxylic acid (ACC) and 1-(4-methoxyphenyl) 3-(4t-butyl phenyl) 1,3 propandione (MBPK) were of high 
purity grade and were used as received. $\mathrm{Sm}^{3+}$-(ACC) and $\mathrm{Sm}^{3+}$-(MBPK) complexes were prepared in different solvents. Pure grade solvents were used, and Polymethylmethacrylate (PMMA) were used as received. PMMA matrix was prepared by dissolving appropriate amount of PMMA in chloroform (8 gm PMMA/50 $\mathrm{ml} \mathrm{CHCl}_{3}$ ) at $30{ }^{\circ} \mathrm{C}$ with vigorous stirring for 15 mins. $\mathrm{Sm}^{3+}$-(ACC) and $\mathrm{Sm}^{3+}$-(MBPK) complexes were incorporated into the PMMA matrix at $30{ }^{\circ} \mathrm{C}$ under vigorous stirring for 15 mins. PMMA thin film was prepared, the thickness of the film was measured using micrometer and it was found to be $0.33 \mathrm{~mm}$.

Absorption spectra were recorded on Heגios Unicam spectrophotometer. A Shimadzu RF-5301 PC Spectrofluorophotometer was used to record the emission spectra.

Luminescence quantum yield $(\Phi)$ was evaluated using the following equation (1) [6]:

$$
\Phi_{\mathrm{u}}=\Phi_{\mathrm{r}} \cdot\left(\mathrm{n}^{2}{ }_{\mathrm{u}} / \mathrm{n}^{2} \mathrm{r}\right) \cdot\left(\mathrm{A}_{\mathrm{r}} / \mathrm{A}_{\mathrm{u}}\right) \cdot\left(\mathrm{F}_{\mathrm{u}} / \mathrm{F}_{\mathrm{r}}\right)
$$

Where $r$ and $u$ stand for reference and unknown, respectively, A is the absorbance of the exciting wavelength, $\mathrm{F}$ is the area under the emission spectrum, $\mathrm{n}$ is the solvent refractive index and $\Phi_{\mathrm{r}}$ is the reference quantum yield $\left(\Phi_{\mathrm{r}}=1\right.$ for Rhodamine 101 in ETOH).

\section{RESULTS AND DISCUSSIONS}

3.1. Absorption spectra. The absorption spectra of ACC $(9 \mu \mathrm{M})$ and MBPK $(30 \mu \mathrm{M})$ in methanol show intense broad bands in the UV region attributed to $\pi-\pi^{*}$ transitions in ACC and MBPK. Figure 1 shows the UV spectrum of ACC in ethanol and similar spectrum was observed for MBPK. These absorption bands upon formation of $\mathrm{Sm}^{3+}$-(ACC) and $\mathrm{Sm}^{3+}{ }_{-}(\mathrm{MBPK})$ complexes are shifted to lower energy, as often observed during complexation of heteroaromatic systems with lanthanide cations [16] (Figure 1 curve 2). The same behavior is obtained in case of other solvents, in mixed solvents methanol/N,N-dimethylformamide and in viscous or polymeric matrix of PMMA.

Moreover, lanthanide ions do not contribute to the spectra of their complexes since f-f transitions are Laporte-forbidden and very weak (molar absorptivity coefficients of the order of only $0.5-3.0 \mathrm{M}^{-1} \mathrm{~cm}^{-1}$ ) [17]. On the other hand, charge-transfer bands involving lanthanide orbitals are also typically not observed in the near-UV and spectral regions [18]. Hence the absorption bands of samarium complexes in different solvents as well as in viscous or polymeric media are completely attributable to the ligand-centered (LC) transitions, although with respect to the corresponding free ligand, some perturbation is observable upon complexation [7].

3.2. Metal-centered photophysical properties. The luminescence of $\mathrm{Ln}^{3+}$-complexes upon excitation

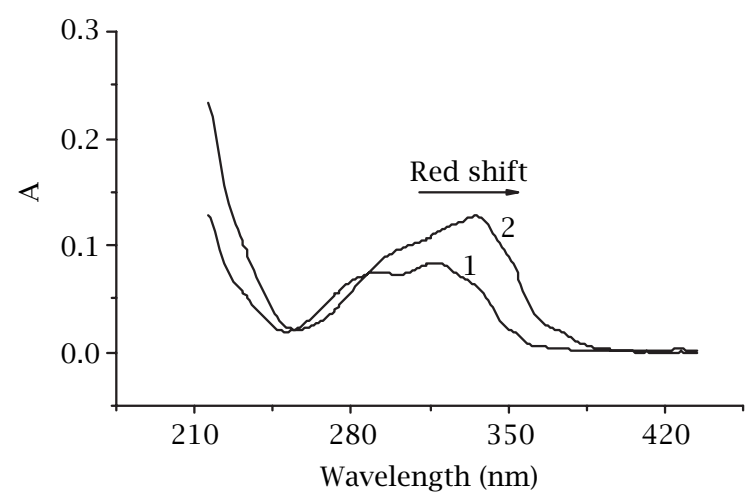

Figure 1. Absorption spectra of: (1) $9 \mu \mathrm{M}$ of ACC (2) $0.15 \mathrm{mM}$ of $\mathrm{Sm}^{3+}$ in presence of $9 \mu \mathrm{M}$ of $\mathrm{ACC}$ in $\mathrm{ETOH}$.

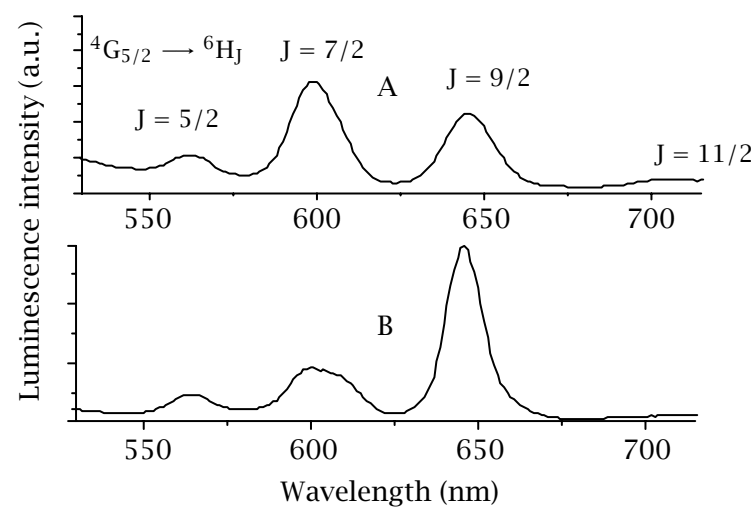

Figure 2. (A) Luminescence spectrum of $0.15 \mathrm{mM} \mathrm{Sm}^{3+}$ in the presence of $9 \mu \mathrm{M} \mathrm{ACC}$ in $\mathrm{EtOH}$. ( $\left.\lambda_{\mathrm{ex}}=365 \mathrm{~nm}\right)$. (B) $\mathrm{Lu}$ minescence spectrum of $10 \mu \mathrm{MSm}^{3+}$ in the presence of $30 \mu \mathrm{M}$ MBPK in $\mathrm{MeOH}$. $\left(\lambda_{\mathrm{ex}}=365 \mathrm{~nm}\right)$.

into the ligand absorption band arises from the f-f transitions of $\mathrm{Ln}^{3+}$ to its lower lying states. The excited $\mathrm{f}-\mathrm{f}$ levels of $\mathrm{Sm}^{3+}$ are populated as a result of energy transfer from the triplet level of ACC or MBPK, which is formed by rapid intersystem crossing [19] $\mathrm{L}_{\mathrm{S}}{ }^{*} \rightarrow \mathrm{L}_{\mathrm{T}}{ }^{*}$ $\left(\mathrm{k}_{\mathrm{ST}} \approx 10^{10} \mathrm{~s}^{-1}\right.$, where $\mathrm{LS}_{\mathrm{S}}{ }^{*}$ and $\mathrm{L}_{\mathrm{T}}{ }^{*}$ are the first excited singlet and triplet ligand states, respectively).

The sensitized luminescence spectrum of the $\mathrm{Sm}^{3+}$. (ACC) $\left(\left[\mathrm{Sm}^{3+}\right]=0.15 \mathrm{mM}\right.$ and $\left.[\mathrm{ACC}]=9 \mu \mathrm{M}\right)$ in $\mathrm{N}, \mathrm{N}-$ dimethylformamide upon ligand excitation at $\lambda_{\mathrm{ex}}=$ $365 \mathrm{~nm}$ is represented in Figure 2 as an example. Similar behavior is obtained in case of $\mathrm{Sm}^{3+}$-(MBPK) $\left(\left[\mathrm{Sm}^{3+}\right]=\right.$ $10 \mu \mathrm{M}$ and $[\mathrm{MBPK}]=30 \mu \mathrm{M})$. The sensitized emis sion spectrum of the $\mathrm{Sm}^{3+}$-(ACC) and $\mathrm{Sm}^{3+}$ (MBPK) shows the characteristic samarium spectrum, which displays four main bands at 17762, 16584, 15361, and $14205 \mathrm{~cm}^{-1}$ corresponding to the ${ }^{4} \mathrm{G}_{5 / 2} \rightarrow{ }^{6} \mathrm{H}_{5 / 2}$ at $564 \mathrm{~nm},{ }^{4} \mathrm{G}_{5 / 2} \rightarrow{ }^{6} \mathrm{H}_{7 / 2}$, at $599 \mathrm{~nm},{ }^{4} \mathrm{G}_{5 / 2} \rightarrow{ }^{6} \mathrm{H}_{9 / 2}$ at $644 \mathrm{~nm},{ }^{4} \mathrm{G}_{5 / 2} \rightarrow{ }^{6} \mathrm{H}_{11 / 2}$ at $707 \mathrm{~nm}$ transitions, respectively [20]. 
Table 1. Emission intensity ratio for $0.15 \mathrm{mM} \mathrm{Sm}^{3+}$ with $9 \mu \mathrm{M} \mathrm{ACC}$ and $10 \mu \mathrm{M} \mathrm{Sm}^{3+}$ with $30 \mu \mathrm{M} \mathrm{MBPK}$ in different solvents, at $25^{\circ} \mathrm{C}\left(\lambda_{\mathrm{ex}}=365 \mathrm{~nm}\right)$.

\begin{tabular}{lcc}
\hline Solvent & $\begin{array}{c}\left.\left(\mathrm{I}^{6} \mathrm{H}_{7 / 2}\right) / \mathrm{I}\left({ }^{6} \mathrm{H}_{9 / 2}\right)\right) \\
\mathrm{Sm}^{3+}-(\mathrm{ACC})\end{array}$ & $\left(\begin{array}{c}\left.\left({ }^{6} \mathrm{H}_{7 / 2}\right) / \mathrm{I}\left({ }^{6} \mathrm{H}_{9 / 2}\right)\right) \\
\mathrm{Sm}^{3+}-(\mathrm{MBPK})\end{array}\right.$ \\
\hline 1. Water & 0.00 & 0.00 \\
2. Methanol & 1.67 & 0.30 \\
3. Ethanol & 1.74 & 0.00 \\
4. n-Butanol & 1.75 & 0.23 \\
5. Acetonitrile & 1.12 & 0.30 \\
6. DMSO & 1.65 & 0.52 \\
7. DMF & 1.65 & 0.52 \\
8. 1,4-dioxane & 1.40 & 0.45 \\
9. Ethylacetate & 1.18 & 0.00 \\
10. Acetone & 0.00 & 0.00 \\
11. Dichloroethane & 1.14 & 0.36 \\
12. Cyclohexane & 0.00 & 0.00 \\
\hline
\end{tabular}

The emission bands of samarium remain narrow even in an organic polymeric matrix and in solution due to the fact that the partially filled $4 \mathrm{f}$ orbitals are shielded from the environment by the filled $5 \mathrm{~s}$ and $5 \mathrm{p}$ orbitals. Similar results are obtained in case of the other solvents.

In the case of samarium metal ion, the intensity, splitting and energy of the luminescence bands as well as the relative intensities of the different bands are very sensitive to the symmetry and the detailed nature of the ligand environment; Figure 2 [21, 22].

\subsubsection{Complex formation and solvent effect on the sensitized luminescence spectra}

Figure 2 shows a magnification of the $564 \mathrm{~nm}, 599 \mathrm{~nm}$, $644 \mathrm{~nm}$ and $707 \mathrm{~nm}$ emission bands corresponding to the ${ }^{4} \mathrm{G}_{5 / 2} \rightarrow{ }^{6} \mathrm{H}_{5 / 2},{ }^{4} \mathrm{G}_{5 / 2} \rightarrow{ }^{6} \mathrm{H}_{7 / 2},{ }^{4} \mathrm{G}_{5 / 2} \rightarrow{ }^{6} \mathrm{H}_{9 / 2}$ and ${ }^{4} \mathrm{G}_{5 / 2} \rightarrow{ }^{6} \mathrm{H}_{11 / 2}$ transitions.

The same behavior is obtained in case of ACC, and emission intensity ratio $\mathrm{I}\left({ }^{6} \mathrm{H}_{7 / 2}\right) / \mathrm{I}\left({ }^{6} \mathrm{H}_{9 / 2}\right)$ of each $\mathrm{Sm}^{3+}$. (ACC) and $\mathrm{Sm}^{3+}$-(MBPK) in different solvents $\left(\lambda_{\mathrm{ex}}=\right.$ $365 \mathrm{~nm}$ ) is reported in Table 1 .

To have a more quantitative measure of the strength of the formed complexes, we applied Benesi and Hildebrand equation [23] (2),

$$
\frac{1}{A_{o b s}-A_{0}}=\frac{1}{A_{c}-A_{0}}+\frac{1}{K_{a p p}\left(A_{c}-A_{0}\right)\left[S^{3+}\right]}
$$

$\mathrm{A}_{\mathrm{obs}}$ : The absorbance of the antenna solution containing different concentrations of samarium ion

$\mathrm{A}_{0}$ : The absorbance of antenna

$\mathrm{A}_{\mathrm{c}}$ : The absorbance of the complex $\left\{\mathrm{Sm}^{3+}\right.$-antenna $\}$ The spectrophotometrically determined formation constants are listed in Table 2 (and obtained graphically from the slopes and intercept of insets in Figures 3
Table 2. Formation constant data of the $\left(\mathrm{Sm}^{3+}-(\mathrm{ACC})\right)$ and $\left(\mathrm{Sm}^{3+}{ }_{-}(\mathrm{MBPK})\right)$ in ethanol at $25^{\circ} \mathrm{C}\left(\lambda_{\mathrm{ex}}=365 \mathrm{~nm}\right)$.

\begin{tabular}{lc}
\hline Complex & $\mathrm{K}, \mathrm{M}^{-1}$ \\
\hline $\mathrm{Sm}^{3+}$-(ACC) & 59.7 \\
$\mathrm{Sm}^{3+}$-(MBPK) & 8.3 \\
\hline
\end{tabular}

Table 3. Emission quantum yield of $0.15 \mathrm{mM} \mathrm{Sm}^{3+}$ with $9 \mu \mathrm{M} \mathrm{ACC}$ and $10 \mu \mathrm{M} \mathrm{Sm}^{3+}$ with $30 \mu \mathrm{M} \mathrm{MBPK}$ in different solvents at $25^{\circ} \mathrm{C}\left(\lambda_{\mathrm{ex}}=365 \mathrm{~nm}\right)$.

\begin{tabular}{lcc}
\hline Solvent & $\Phi_{\left(\mathrm{Sm}^{3+} \text {-(ACC) }\right.}$ & $\Phi_{\left(\mathrm{Sm}^{3+}{ }_{-(\mathrm{MBPK}))}\right.}$ \\
\hline 1. Water & 0.000 & 0.000 \\
2. Methanol & 0.043 & 0.004 \\
3. Ethanol & 0.039 & 0.002 \\
4. n-Butanol & 0.045 & 0.008 \\
5. Acetonitrile & 0.030 & 0.005 \\
6. DMSO & 0.039 & 0.009 \\
7. DMF & 0.099 & 0.012 \\
8. 1,4-dioxane & 0.031 & 0.000 \\
9. Ethylacetate & 0.000 & 0.000 \\
10. Acetone & 0.022 & 0.010 \\
11. Dichloroethane & 0.000 & 0.000 \\
12. Cyclohexane & 0.010 & 0.000 \\
\hline
\end{tabular}

and 4). It is clear that strong complexes are formed and the data shows that $\mathrm{K}\left(\mathrm{Sm}^{3+}-(\mathrm{ACC})\right)$ is larger than $\mathrm{K}\left(\mathrm{Sm}^{3+}-(\mathrm{MBPK})\right)$.

This is reflected in the quantum yields of the sensitized emission of $\mathrm{Sm}^{3+}{ }_{-}(\mathrm{ACC})$ and $\mathrm{Sm}^{3+}$ (MBPK) in dimethylformamide aerated solutions, which are given in Table 3. Data in Table 2 is consistent with data of Table 3 and show that ACC antenna is clearly the more efficient sensitizer for $\mathrm{Sm}^{3+}$ than MBPK.

Moreover, the sensitized luminescence of $\mathrm{Sm}^{3+}$. (ACC) $\left(\left[\mathrm{Sm}^{3+}\right]=0.15 \mathrm{mM},[\mathrm{ACC}]=9 \mu \mathrm{M}\right)$ and $\mathrm{Sm}^{3+}$. $(\mathrm{MBPK})\left(\left[\mathrm{Sm}^{3+}\right]=10 \mu \mathrm{M}\right.$ and $\left.[\mathrm{MBPK}]=30 \mu \mathrm{M}\right) \mathrm{com}-$ plexes in water and alcohols (solvents containing $\mathrm{O}-\mathrm{H}$ bonds) is inefficient $\lambda$, which is attributed to the radiative and nonradiative decay processes of the $\mathrm{Sm}^{3+}$ ${ }^{4} \mathrm{G}_{5 / 2}$ emitting state. Nonradiative deactivation via vibronic coupling is very common for lanthanide ions coordinated by solvent molecules containing high-energy $\mathrm{OH}$ oscillators $[11,24,25]$. Complete quenching of the sensitized luminescence of $\mathrm{Sm}^{3+}$-(ACC) and $\mathrm{Sm}^{3+}$. (MBPK) observed in water and low quantum yield values are obtained in alcoholic solvents (Table 3). Consequently, the energy of the excited ligand state being transferred onto the metal ion, but the energy is then partially or completely dissipated through nonradiative processes via vibronic coupling with the O-H [11] $\left(v_{\mathrm{sym}}=3500 \mathrm{~cm}^{-1}\right)$ oscillators of water and alcohols.

In case of $\mathrm{Sm}^{3+}$-(MBPK) in 1,4-dioxane and $\mathrm{Sm}^{3+}$. (ACC) in ethylacetate also complete quenching is 


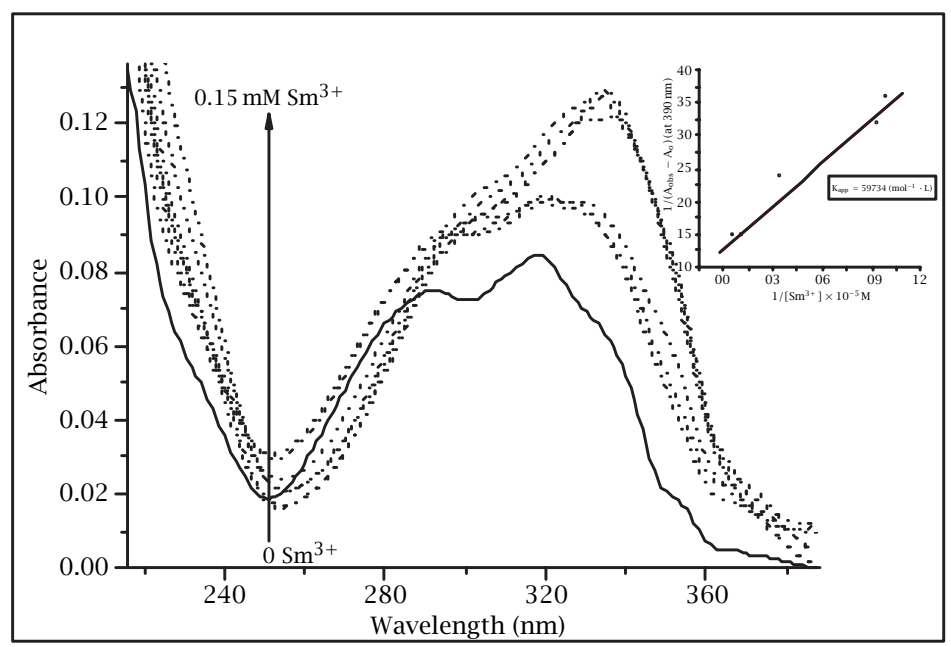

Figure 3. Absorption spectrum of $9 \mu \mathrm{M}$ ACC in presence of different concentrations of $0.15 \mathrm{mM} \mathrm{Sm}^{3+}$ in ethanol.

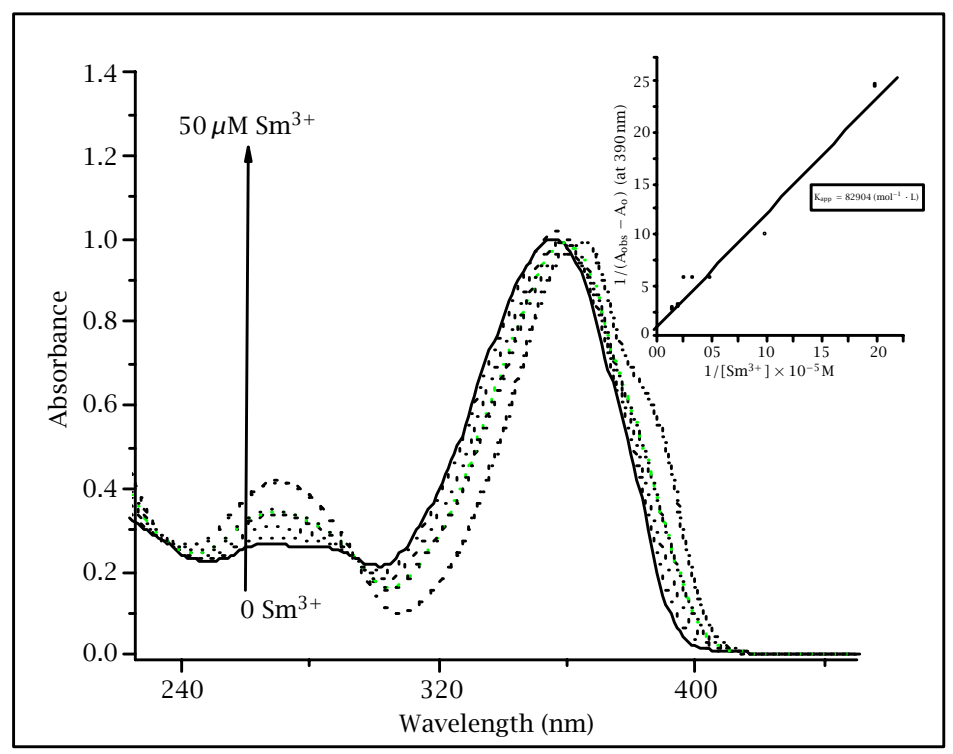

Figure 4. Absorption spectrum of $30 \mu \mathrm{M} \mathrm{MBPK}$ in presence of different concentrations of $50 \mu \mathrm{M} \mathrm{Sm}^{3+}$ in ethanol.

observed (quantum yield values $\simeq 0$ ) and weak luminescence is observed in acetone for both ligands. These results may indicate that the energy transfer does occur from the ligand to the $\mathrm{Sm}^{3+}$ ion, but the energy is then dissipated through nonradiative processes from ligand to the solvent [22].

The $\mathrm{C}=\mathrm{O} \quad\left(v_{\mathrm{C}=\mathrm{O}}=1700 \mathrm{~cm}^{-1}\right)$ or $\mathrm{C}-\mathrm{H} \quad\left(v_{\mathrm{sym}}=\right.$ $2900 \mathrm{~cm}^{-1}$ ) groups quench the excited state in a manner similar to that of coordinated azide ion [27]. However, even in 1,4-dioxane a solvent that is known to effectively displace water and alcohol molecules from the inner coordination sphere of the lanthanide ion [19], the $\mathrm{Sm}^{3+}$-(MBPK) studied show no luminescence efficiency indicating that excited ligand is quenched by the vibrations of $\mathrm{C}-\mathrm{H}$ of 1,4-dioxane.

In general, higher quantum yield values are obtained for $\left(\mathrm{Sm}^{3+}\right.$-(ACC)) (Table 3) in almost all solvents indicating a high efficiency of the ligand-metal energy transfer for this chromophore.

\subsubsection{Effect of mixed solvent}

The sensitized luminescence emission spectrum of $\mathrm{Sm}^{3+}$ in presence of $\mathrm{MBPK}(30 \mu \mathrm{M})$ in DMF at various methanol concentrations is shown in Figure 5. Same behavior is obtained in case of ACC. Addition of 


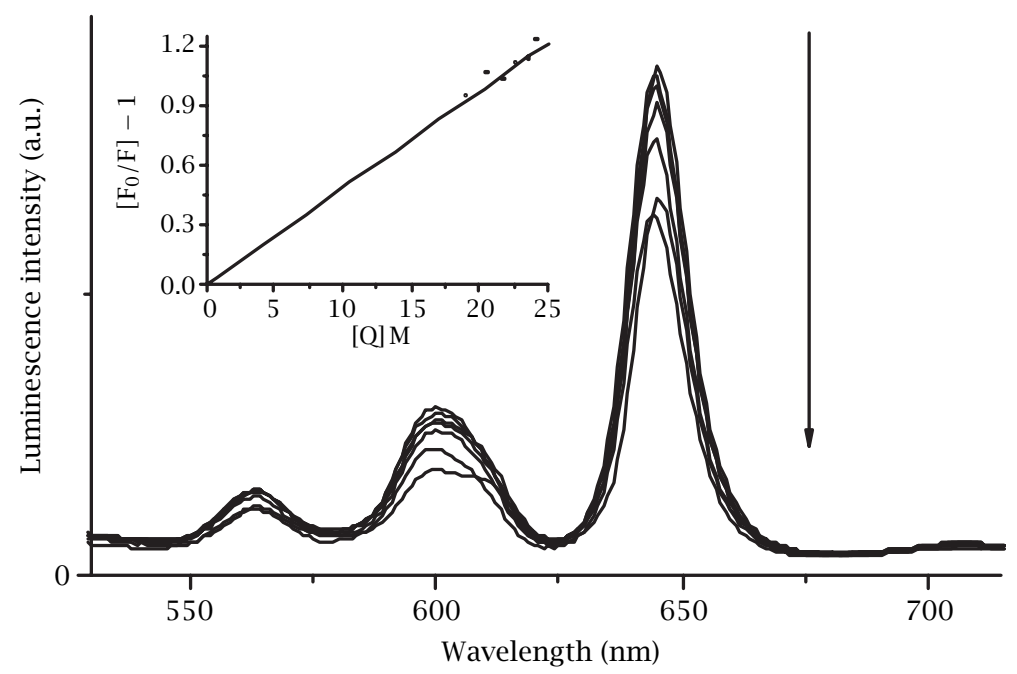

Figure 5. Quenching of the $644 \mathrm{~nm}$ emission band of $\mathrm{Sm}^{3+}$ in the presence of $\mathrm{MBPK}$ by different concentrations of $\mathrm{MeOH}$ in DMF. Inset shows Stern-Volmer plot $\left(\lambda_{\mathrm{ex}}=365 \mathrm{~nm}\right)$.

Table 4. Stern-Volmer constants, critical concentration, and critical radius of $\mathrm{Sm}^{3+}(\mathrm{ACC})$ and $\mathrm{Sm}^{3+}-(\mathrm{MBPK})$ Complexes.

\begin{tabular}{lccc}
\hline Complex & $\mathrm{K}_{\mathrm{SV}}\left(\mathrm{l} \mathrm{mol}^{-1}\right)$ & $\mathrm{C}_{01 / 2}\left(\mathrm{~mol} \mathrm{l}^{-1}\right)$ & $\mathrm{R}_{0}(\AA)$ \\
\hline $\mathrm{Sm}^{3+}$-(ACC) & 0.9304 & 1.074 & 6.83 \\
$\mathrm{Sm}^{3+}$-(MBPK) & 0.9517 & 1.050 & 7.23 \\
\hline
\end{tabular}

methanol to DMF solutions of $\left(\mathrm{Sm}^{3+}{ }_{-}(\mathrm{ACC})\right)$ and $\left(\mathrm{Sm}^{3+}\right.$. (MBPK)) quenched the sensitized $\mathrm{Sm}^{3+}$ luminescence intensity upon excitation at $\left(\lambda_{\mathrm{ex}}=365 \mathrm{~nm}\right)$. These results are a consequence of the large nonradiative deactivation effects of the $\mathrm{O}-\mathrm{H}$ oscillators of the methanol molecules [11], which interact with the first and second coordination sphere of $\mathrm{Sm}^{3+}$.

The luminescence quenching efficiency is evaluated by Stern-Volmer constant $\left(\mathrm{K}_{\mathrm{SV}}\right)$. Quenching plots are constructed according to the following Stern-Volmer equation (3) [27]:

$$
\left(\mathrm{F}_{0} / \mathrm{F}\right)-1=\mathrm{K}_{\mathrm{SV}}[\mathrm{Q}]
$$

where $\mathrm{F}_{0}$ and $\mathrm{F}$ are the luminescent intensity in absence and presence of quencher, respectively, $\mathrm{K}_{S V}$ is the Stern-Volmer constant and $[\mathrm{Q}]$ is the quencher concentration, The linear plot of $\left[\mathrm{F}_{0} / \mathrm{F}\right]-1$ versus $[\mathrm{Q}]$ (inset of Figure 5), indicates that luminescence quenching is dynamic in nature. From the slope of the fitted data the Stern-Volmer constants $\mathrm{K}_{S V}$ can be calculated (Table 4).

Moreover, an apparent critical concentration $\left[\mathrm{C}_{01 / 2}\right]$ for luminescence quenching can be experimentally determined. This parameter is defined as the acceptor concentration at which the luminescence quantum yield of the donor is reduced to $0.5 \Phi_{0}$ [28], eq. (4)

$$
\mathrm{C}_{01 / 2}=1 / \mathrm{K}_{\mathrm{sv}}
$$

Table 5. Quantum yields of the $\left.\mathrm{Sm}^{3+}{ }_{-} \mathrm{ACC}\right)$ and $\mathrm{Sm}^{3+}$ (MBPK) in PMMA ( $\left.\lambda_{\mathrm{ex}}=365 \mathrm{~nm}\right)$.

\begin{tabular}{lc}
\hline Complexes & PMMA \\
\hline $\mathrm{Sm}^{3+}$-(ACC) & 0.270 \\
$\mathrm{Sm}^{3+}$-(MBPK) & 0.150 \\
\hline
\end{tabular}

The corresponding apparent critical radius [29] $\left(\mathrm{R}_{0}\right)$ can also be calculated from eq. (5):

$$
\mathrm{R}_{0}=7.35 /\left[\mathrm{C}_{01 / 2}\right]^{1 / 3}
$$

The calculated critical concentrations and the corresponding critical radii calculated by eqs. (4) and (5) are listed in Table 4.

Since the calculated critical radii $\mathrm{R}_{0}<10 \mathrm{~A}^{\circ}$, it could be concluded that the quenching process is of the exchange type (i.e., Dexter type), which requires direct contact of donor and acceptor.

\subsubsection{Effect of inclusion in polymeric matrix of PMMA}

Furthermore, same sensitized emission spectrum $\left(\lambda_{\mathrm{ex}}=365 \mathrm{~nm}\right)$ of the polymer (PMMA) doped with $\mathrm{Sm}^{3+}$-(ACC) or $\mathrm{Sm}^{3+}$-(MBPK) complexes was observed and show the typical narrow emission bands corresponding to the $\mathrm{Sm}^{3+}$-centered ${ }^{4} \mathrm{G}_{5 / 2} \rightarrow{ }^{6} \mathrm{H}_{\mathrm{J}}$ transitions with the strongest emission located around $564 \mathrm{~nm}$ originating from ${ }^{4} \mathrm{G}_{5 / 2} \rightarrow{ }^{6} \mathrm{H}_{5 / 2}$ transitions. Also according to ${ }^{4} \mathrm{G}_{5 / 2} \rightarrow{ }^{6} \mathrm{H}_{7 / 2}$ transition at $599 \mathrm{~nm}$, no splitting is observed when perturbed by the polymer around $\mathrm{Sm}^{3+}$.

The enhancement of the sensitized luminescence quantum yields of $\mathrm{Sm}^{3+}$ observed in PMMA matrix for both ligands (Table 5 ) reflect the higher hypersensitivity behavior of the ${ }^{4} \mathrm{G}_{5 / 2} \rightarrow{ }^{6} \mathrm{H}_{7 / 2}$ transition. The results 


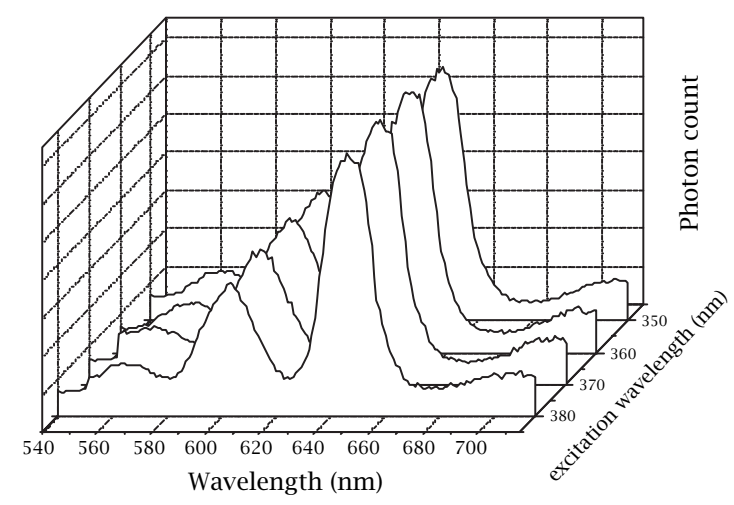

Figure 6. 3D-View of the emission spectrum of samarium ion in $\left(\mathrm{Sm}^{3+}{ }_{-}(\mathrm{MBPK})\right)$ complex in $\mathrm{DMF}$ at different excitation wavelengths.

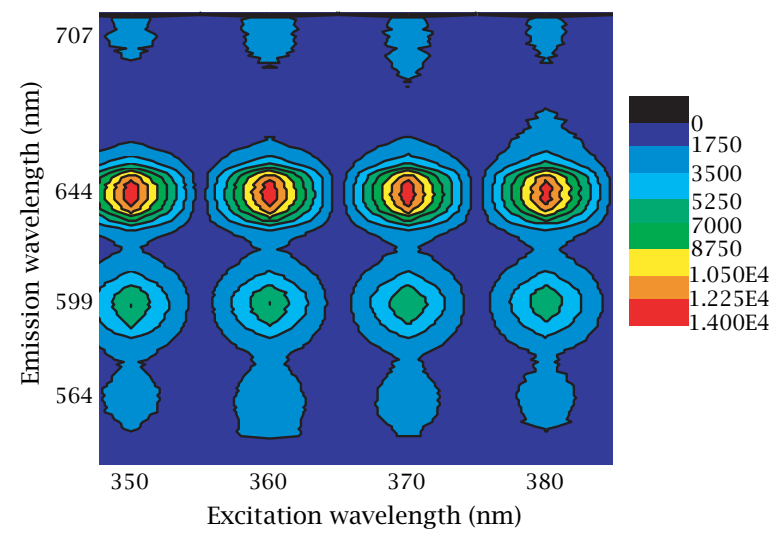

Figure 7. Contour view of the emission spectra of $\mathrm{Sm}^{3+}$ ion in $\left(\mathrm{Sm}^{3+}-(\mathrm{MBPK})\right)$ complex in DMF at different excitation wavelengths.

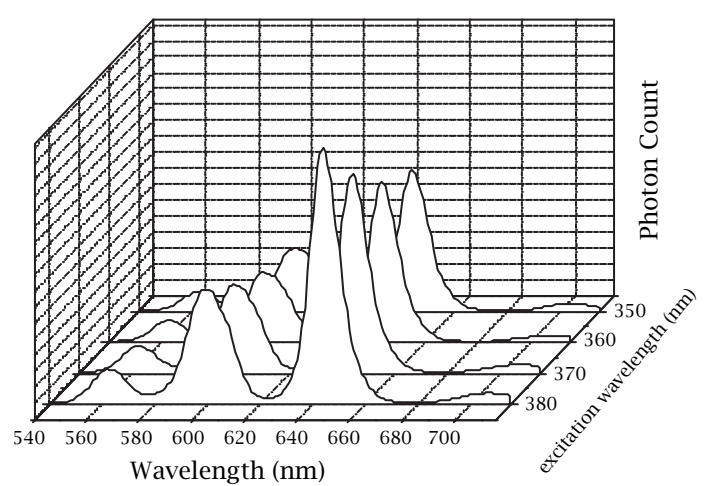

Figure 8 . 3D-View of the emission spectrum of samarium ion in $\left(\mathrm{Sm}^{3+}\right.$-(MBPK) ) complex in $\mathrm{MeOH}$ at different excitation wavelengths.

can be interpreted in terms of free-volume availability in PMMA matrix, which inhibits the vibration of the

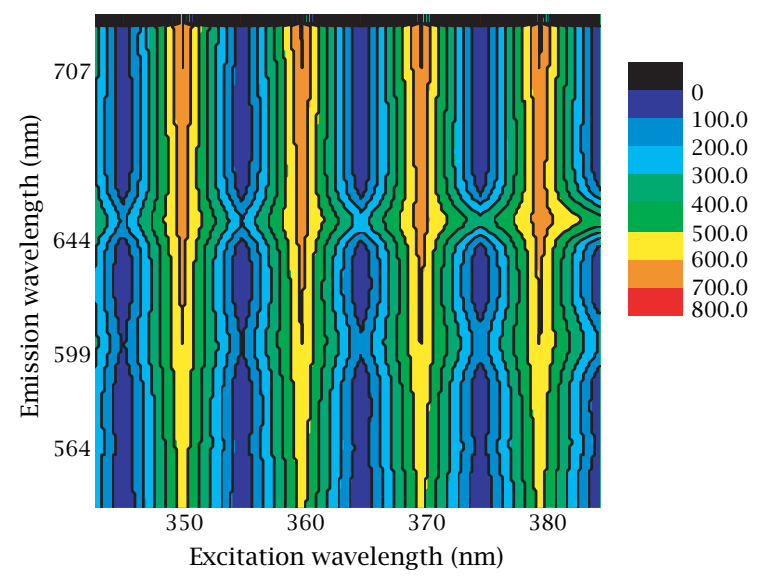

Figure 9. Contour view of the emission spectra of $\mathrm{Sm}^{3+}$ ion in $\left(\mathrm{Sm}^{3+}-(\mathrm{MBPK})\right)$ complex in $\mathrm{MeOH}$ at different excitation wavelengths.

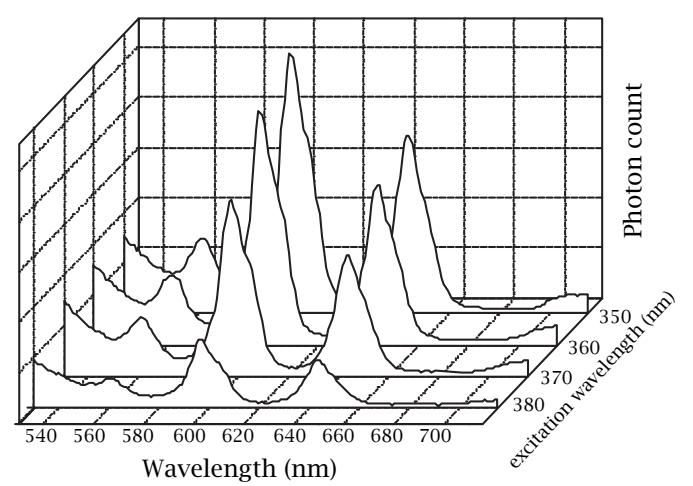

Figure 10. 3D-View of the emission spectra of samarium ion in $\mathrm{Sm}^{3+}$-(ACC) complex in DMF at different excitation wavelengths.

ligand around $\mathrm{Sm}^{3+}$ ion and as a result the luminescence intensity and quantum yield are increased in the rigid medium.

3.3. Mapping as fingerprint. A three dimensional plot could be exploited profitably as a powerful analytical tool and is required for a complete description of the luminescence, which are given in Figures 6,8 , and 10 . It may be represented as the so-called excitation/emission matrix [30, 31].

Furthermore, connection of data points with the same luminescence intensity (i.e., same height) by lines results in tomograms of two-dimensional representation (luminescence mapping). Such diagrams always represent a top view [31] as in Figures 7, 9, and 11.

This method seems to be useful as a qualitative identification tool. In particular, the location and relative intensity of peaks are suitable parameters for pattern recognition analysis as well as a useful 


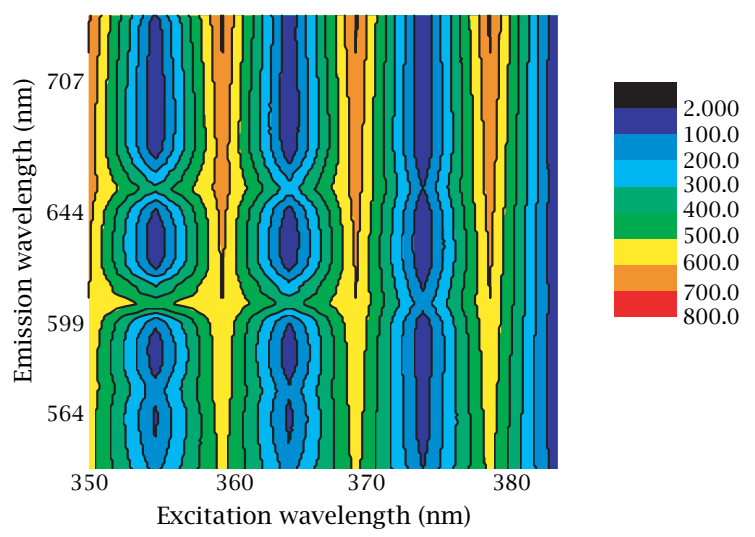

Figure 11. Contour view of the emission spectra of $\mathrm{Sm}^{3+}$ ion in $\left.\left(\mathrm{Sm}^{3+}{ }_{-} \mathrm{ACC}\right)\right)$ complex in $\mathrm{DMF}$ at different excitation wavelengths.

identification method in clinical chemistry and biochemistry [32-35]. The nature of the solvent and the ligand is clearly identified by inspection of the corresponding excitation/emission matrix maps in Figures 7, 9 , and 11 .

\section{CONCLUSIONS}

We have shown that the photophysical properties of samarium ion in presence of ACC or MBPK antenna molecules are sensitive to the nature of the medium whether it is homogeneous, heterogeneous or rigid PMMA. High quantum yield value of the sensitized emission of $\left(\mathrm{Sm}^{3+}-(\mathrm{ACC})\right)$ and $\left(\mathrm{Sm}^{3+}-(\mathrm{MBPK})\right)$ in $\mathrm{N}, \mathrm{N}-$ dimethylformamide and PMMA matrix are obtained pointing to an efficient ligand-to-metal energy transfer. Low luminescence intensity observed in case of protic solvents are due to radiationless energy dissipation via vibronic coupling with the $\mathrm{O}-\mathrm{H}$ oscillators of water and alcohols. The determined $1: 1$ complex formation constant shows that $\mathrm{K}\left(\mathrm{Sm}^{3+}-(\mathrm{ACC})\right)>\mathrm{K}\left(\mathrm{Sm}^{3+}-(\mathrm{MBPK})\right)$, which explains the obtained high quantum yield value for $\mathrm{Sm}^{3+}$-(ACC) indicating more efficient ligand-metal energy transfer for this chromophore. Moreover, luminescence mappings for pattern recognition analysis that could be profitably exploited as a useful identification method in clinical chemistry and biochemistry have been obtained from which the nature of the solvent and/or the ligand is clearly identified by inspection of the corresponding excitation/emission matrix maps.

\section{REFERENCES}

[1] E. F. G. Dickson, A. Pollack, and E. P. Diamandis, J. Photochem. Photobiol. B: Biol. 27 (1995), 3.

[2] M. Elbanowski and B. Makowska, J. Photochem. Photobiol. A: Chem. 99 (1996), 85.
[3] P. G. O. Wolbers, F. C. J. M. van Veggel, F. G. A. Perters, E. S. E. van Beelen, J. W. Hofstaraat, F. A. J. Geurts, and D. N. Reinhoudt, Chem. Eur. J. 4 (1998), 772.

[4] G. R. Choppin and D. R. Peterman, Coord. Chem. Rev. 174 (1998), 283.

[5] D. Xdparker, Coord. Chem. Rev. 205 (2000), 109.

[6] S. I. Klink, L. Grave, D. N. Reinhoudt, F. C. J. M. van Veggel, M. H. V. Werts, F. A. J. Geurts, and J. W. Hofstraat, J. Phys. Chem. A 104 (2000), 5457.

[7] N. Sabbatini, A. Casnati, C. Fischer, R. Girardini, M. Guardigli, I. Manet, G. Sati, and R. Ungaro, Inorg. Chem. Acta. 252 (1996), 19.

[8] J. M. Lehn, Angew. Chem. Int. Ed. Engl. 29 (1990), 1304.

[9] M. Xiao and P. R. Selvin, J. Am. Chem. Soc. 123 (2001), 7067.

[10] G. Mathis, Clin. Chem. 41 (1995), 1391.

[11] D. Parker, Coord. Chem. Rev. 205 (2000), 109.

[12] J. Chen and P. R. Selvin, J. Photochem. and Photobiol. A: Chem. 135 (2000), 27.

[13] R. Zhu and T. W. Kok, Anal. Chem. 69 (1997), 4010.

[14] I. K. Hemmila, Applications of Fluorescence in Immunoassays, Wiley and Sons, New York, 1991.

[15] G. Mathis, Clin. Chem. 41 (1995), 1391.

[16] D. Parker, Coord. Chem. Rev. 205 (2000), 109.

[17] N. Armaroli, G. Accorsi, F. Barigelletti, S. M. Couchman, J. S. Fleming, N. C. Harden, J. C. Jeffery, K. L. V. Mann, J. A. McCleverty, L. H. Rees, S. R. Starling, and M. D. Ward, Inorg. Chem. 38 (1999), 5769.

[18] J. C. G. Bunzli, L. J. Charbonniere, and R. F. Ziessel, J. Chem. Soc. Dalton trans. (2000), 1917.

[19] A. I. Voloshin, N. M. Shavaleev, and V. P. Kazakov, J. Lumin. 93 (2001), 199.

[20] Fabiana R. Goncüalves e Silva, Oscar L. Malta, Christine Reinhard, Hans-Ulrich Gudel, Claude Piguet, Jacques E. Moser, and Jean-Claude G. Bunzli, J. Phys. Chem. A 106 (2002), 1670.

[21] J.-C. G. Bunzli, Lanthanide Probes in Life, Chemical and Earth Sciences. Theory and Practice (J.-C. G. Bunzli and G. R. Choppin, eds.), Elsevier Science, Amsterdam, 1989.

[22] Stefan Lis, Journal of Alloys and Compounds 341 (2002), 45.

[23] H. A. Benesi and J. H. Hildebrand, J. Am. Chem. Soc. 71 (1949), 2703.

[24] Y. Haas, G. Stein, and E. Wurzberg, J. Chem. Phys. 60 (1974), 258.

[25] G. Stein and E. Wulrzberg, J. Chem. Phys. 62 (1975), 208.

[26] H. J. Zhang, L. S. Fu, S. B. Wang, Q. G. Meng, K. Y. Yang, and J. Z. Ni, Materials Lett. 38 (1999), 260.

[27] O. Stern and M. Volmer, Physik. Z. 20 (1919), 183.

[28] F. L. Arbeloa, P. R. Ojeda, and I. L. Arbeloa Photochem. and Photobiol. A: Chem. 27 (1988), 1628.

[29] H. M. McConnell, J. Chem. Phys. 35 (1961), 508. 
[30] O. S. Wolfbeis and M. leinear, Anal. Chem. Acta 104 (1983), 203.

[31] G. D. Christian, J. B. Callis, and E. R. Davidson, Modern Fluorescence Spectroscopy, 4, (E. L. Wehry, ed.), Plenum Press, New York, (1981), Ch. 4.

[32] I. M. Warner, J. B. Callis, E. R. Davidson, and G. D. Christian, Clin. Chem. 22 (1976), 1483.

[33] R. O. Nodari, S. M. Tsai, and R. L. Gilbertson, Gepts, P. 85 (1993), 513.
[34] K. Schumann, A. Baumann, and W. Nagl, Localization of phaseolin genes in the polytene chromosomes of phaseolus coccineus (Leguminase). Genetica 83 (1990), 73.

[35] J. Jian, B. S. Gill, G. Wang, P. C. Ronald, and D. C. Ward, Proc. Natl. Acad. Sci. USA 92 (1995), 4487. 


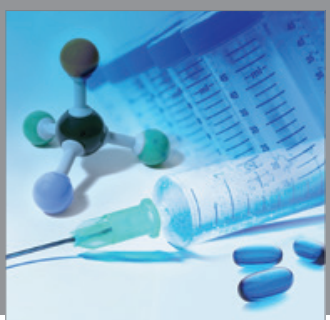

International Journal of

Medicinal Chemistry

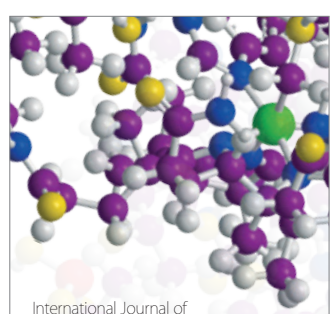

Carbohydrate Chemistry

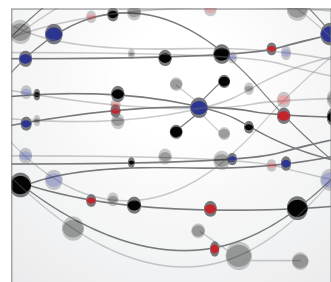

The Scientific World Journal
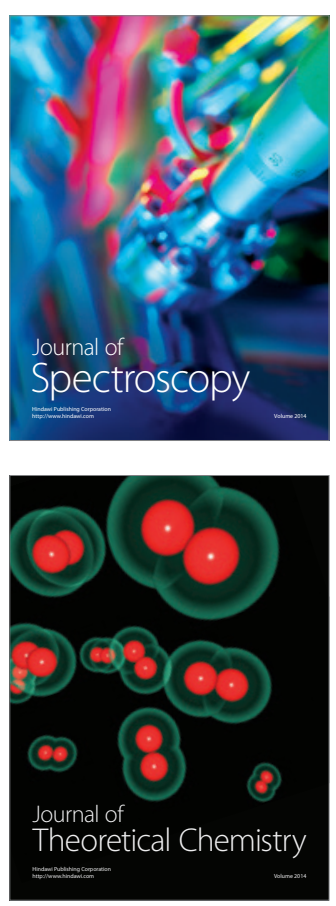
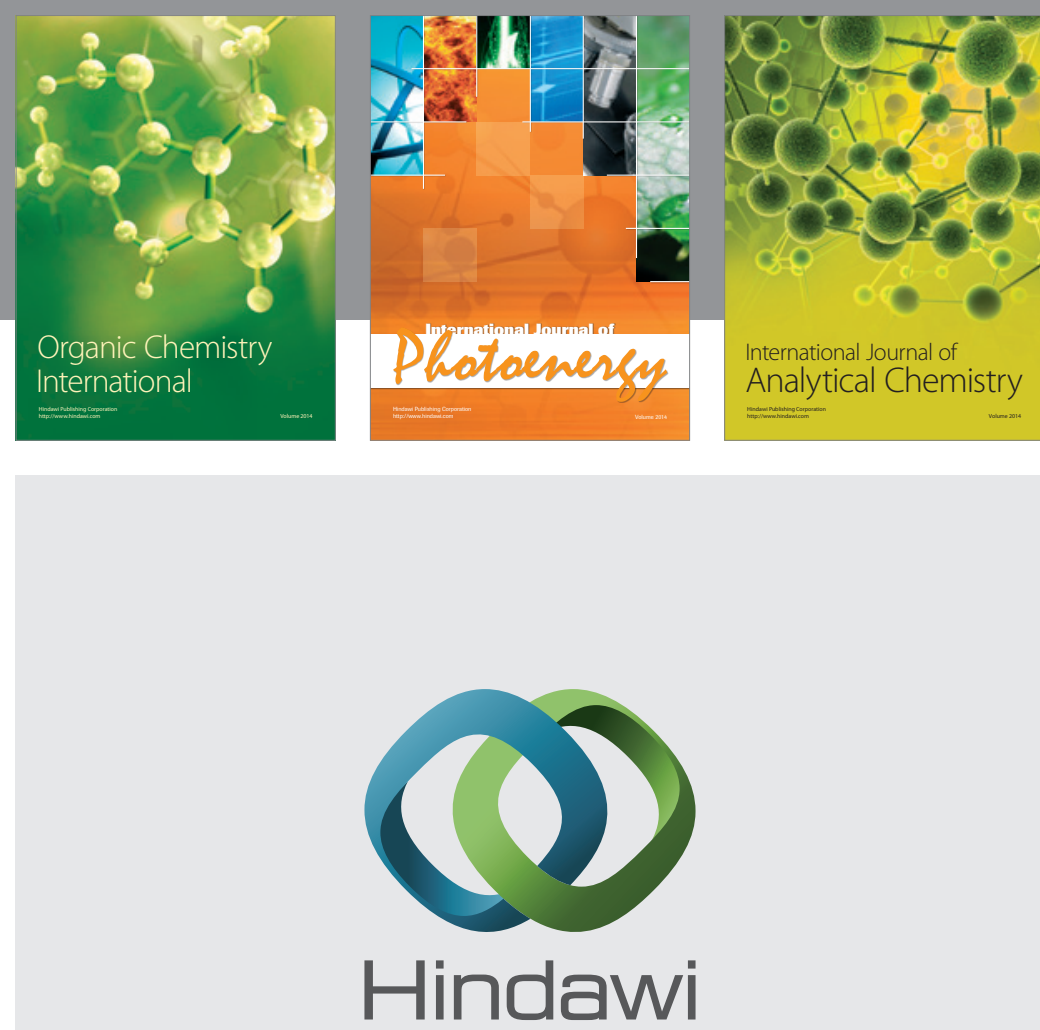

Submit your manuscripts at

http://www.hindawi.com
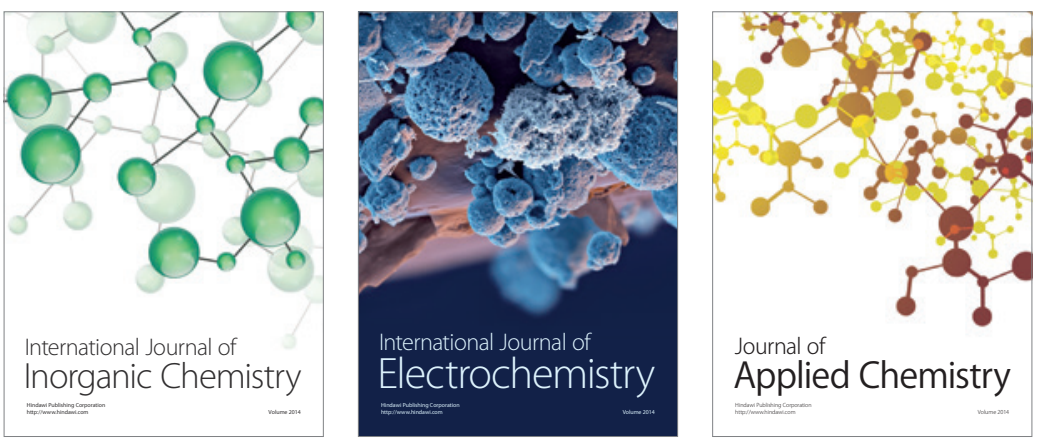

Journal of

Applied Chemistry
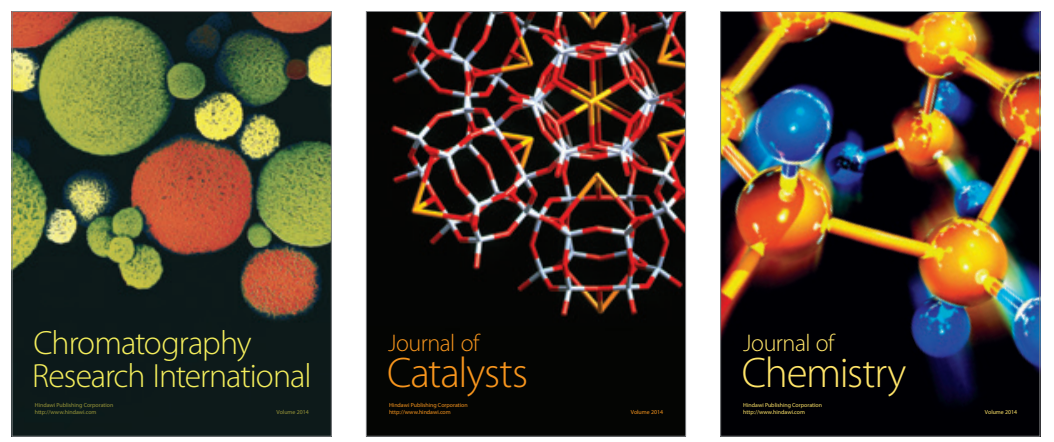
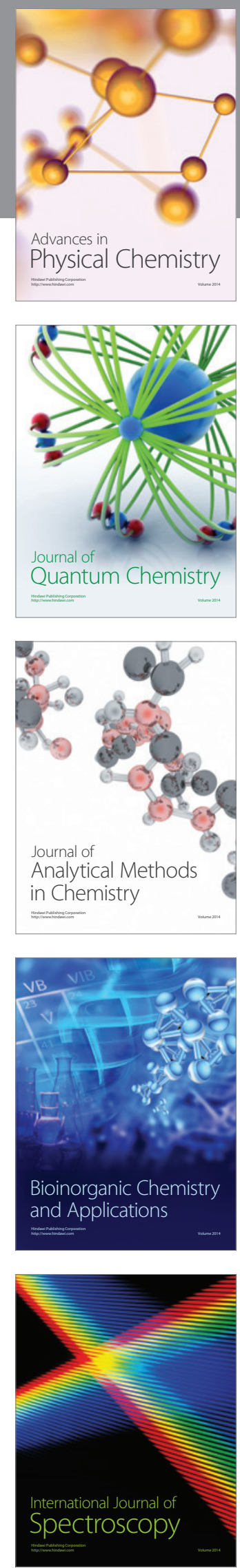